\title{
Comportamento de genótipos de arroz de terras altas no estado de São Paulo'
}

\author{
Behavior of upland rice genotypes in the state of São Paulo, Brazil
}

\author{
Amadeu Regitano Neto ${ }^{2 *}$, Edson Ulisses Ramos Junior ${ }^{3}$, Paulo Boller Gallo ${ }^{4}$, José Guilherme de Freitas ${ }^{2}$ e Luiz \\ Ernesto Azzini²
}

\begin{abstract}
RESUMO - O desempenho de linhagens promissoras de arroz, gerado pelo programa de melhoramento genético do Instituto Agronômico (IAC) foi avaliado em diferentes ambientes. Os ensaios foram instalados em blocos casualizados com quatro repetições e parcelas experimentais com área útil de $6 \mathrm{~m}^{2}$ nos anos agrícolas de 2006/2007, 2007/2008, 2008/2009 e 2009/2010, nos municípios de Capão Bonito-SP e Mococa-SP. A variação total dos dados de produção de grãos foi analisada pela ANAVA e pela ANADEV, e foram estimadas as significâncias dos efeitos da interação genótipo $\mathrm{x}$ ambiente pelas duas metodologias. A adaptabilidade e estabilidade de 16 genótipos de arroz de terras altas em 8 ambientes foram avaliadas pelos métodos de Eberhart e Russell (1966) e Lin e Binns (1988) e pela metodologia dos modelos mistos (REML/BLUP). Pelo método da média harmônica da performance relativa dos valores genotípicos (MHPRVG) foram selecionadas as linhagens IAC 2009, IAC 1829 e IAC 2005 com produções superiores em 11; 10 e 6\% respectivamente, em relação à média geral, o que foi coincidente com os resultados obtidos pelas outras metodologias.
\end{abstract}

Palavras-chave: Arroz-melhoramento genético. Interação genótipo-ambiente.

\begin{abstract}
The performance of promising strains of rice, generated through the genetic improvement program of the Instituto Agronômico (IAC), was evaluated for different environments. The experiments were set up in a randomizedblock design with four replications, using experimental plots of $6 \mathrm{~m}^{2}$, during the periods 2006/2007, 2007/2008, 2008/2009 and 2009/2010, in the municipalities of de Capão Bonito and Mococa, both in São Paulo. The total variation of the data for grain-production was analyzed using ANAVA and ANADEV, and the significance of the effects of the interaction between genotype and environment were estimated for the two methodologies. The adaptability and stability of 16 genotypes of upland rice in eight environments were evaluated using the methods of Eberhart and Russell (1966), Lin and Binns (1988), and mixed-model (REML / BLUP). Using the harmonic mean of the relative performance of genotypic values (MHPRVG), the strains, IAC 2009, IAC 1829 and IAC 2005 were selected, with yields superior to 11; 10 and $6 \%$ respectively when compared to the general average, which matched results obtained by other methods.
\end{abstract}

Key words: Rice breeding. Genotype environment interaction.

\footnotetext{
* Autor para correspondência

${ }^{1}$ Recebido para publicação em 14/09/2011, aprovado em 16/12/2012

Trabalho desenvolvido pelo Programa de Melhoramento de Arroz do Instituto Agronômico

${ }^{2}$ Centro de Análise e Pesquisa Tecnológica do Agronegócio de Grãos e Fibras, Instituto Agronômico/IAC, Campinas, SP, Brasil, Caixa Postal 28,

13.012-970, regitano@iac.sp.gov.br, jfreitas@iac.sp.gov.br, leazzini@uol.com.br

${ }^{3}$ APTA Regional Sudoeste Paulista, Caixa Postal 62, Capão Bonito-SP, Brasil, 18.300-970. edison@apta.sp.gov.br

${ }^{4}$ APTA Regional Nordeste Paulista, Caixa Postal 58, Mococa-SP, Brasil. 13.730-972.paulogallo@apta.sp.gov.br
} 


\section{INTRODUÇÃO}

Estudos de adaptabilidade e estabilidade têm evidenciado a grande importância e as dificuldades de se tratar a interação genótipos por ambientes (IGA), isto é, quando os genótipos não mantêm o mesmo desempenho relativo nos diferentes ambientes em que são cultivados. Assim, como o propósito de um programa de melhoramento genético de plantas é selecionar genótipos estáveis e de elevada produtividade em diversos ambientes, a interação representa um problema, exigindo eficiência na análise e que as comparações das metodologias sejam realizadas para se escolher a mais apropriada.

Metodologias de análise de estabilidade e adaptabilidade têm sido utilizadas para análise de séries de ensaios de programas de melhoramento de arroz (BORGES et al., 2010; MORAIS et al., 2008;), feijão (CARBONELL et al., 2007), alfafa (FERREIRA et al., 2004), entre outras espécies. Atualmente estão disponíveis diferentes métodos para a estimativa desses parâmetros, entre os quais os propostos por Eberhart e Russell (1966), no qual a adaptabilidade é obtida pela estimativa do coeficiente de regressão linear $\left(\beta_{1 \mathrm{i}}\right)$ e a estabilidade pelos desvios da regressão $\left(\sigma_{\mathrm{di}}^{2}\right)$, além da metodologia de Lin e Binns (1988) que compara o comportamento de cada linhagem com a maior média em cada ambiente, sendo que a menor estimativa do parâmetro $\left(\mathrm{P}_{\mathrm{i}}\right)$ indica o material com melhor produtividade, adaptabilidade e estabilidade. Essas metodologias fornecem estimativas com base em observações fenotípicas, o que inclui o componente ambiental e o genotípico. A análise realizada por meio da metodologia de modelos mistos, também chamada método REML/BLUP foi proposta para culturas perenes como eucalipto e pinus (BUENO FILHO; VENCOVSKY, 2000; RESENDE et al., 1996) e sua aplicação tem se disseminado na análise de informações de diversas culturas tanto perenes como anuais (RESENDE, 2004). O procedimento REML (Restricted Maximum Likelihood), ou máxima verossimilhança restrita, estima componentes de variância necessários ao modelo e o BLUP, (Best Linear Unbiased Prediction), melhor preditor linear não viesado, estima o valor genotípico.

Vencovsky e Barriga (1992) mostraram que no melhoramento, a ocorrência de IGA significativa não é desejável, pois dificulta a obtenção de ganhos genéticos pela seleção. Nesse sentido a utilização de métodos acurados, somente possíveis devido às implementações computacionais da junção REML/BLUP ou somente do BLUP tem surgido avaliações com base em valores genotípicos preditos livres dos efeitos ambientais (BASTOS et al., 2007; CARBONELL et al., 2007; MORA;PUPIMJÚNIOR;SCAPIM, 2007; OLIVEIRA etal.,2005; PIEPHO; MÖHRING, 2005; PURB Aetal., 2001; YAN; RAJCAN, 2003). Além desta, destacam-se outras vantagens do REML/BLUP (RESENDE, 2007a), ou seja: permite comparar indivíduos ou linhagens através do tempo e espaço; permite a simultânea correção para os efeitos ambientais, estimação de componentes de variância e predição de valores genéticos; permite lidar com estruturas complexas de dados, dados desbalanceados e delineamentos não ortogonais, além de outras vantagens, gerando estimativas e predições mais precisas; permite o ajuste para modelos alternativos, podendo-se escolher aquele que se ajusta melhor aos dados e, ao mesmo tempo, ser parcimonioso, ou seja, pode ser estruturado utilizandose menor número de parâmetros.

Desta forma, o presente trabalho teve como objetivo selecionar linhagens superiores de arroz do programa de melhoramento genético do Instituto Agronômico (IAC) por meio de diferentes metodologias, visando-se obter maior consistência nas informações quanto à estabilidade, adaptabilidade e produtividade, facilitando a escolha destas para as condições edafoclimáticas do estado de São Paulo.

\section{MATERIAL E MÉTODOS}

Neste trabalho foram analisados os resultados de produtividade de grãos de ensaios de valor de cultivo e uso, utilizando-se 13 linhagens avançadas e três variedades comerciais como testemunhas, nos anos agrícolas de 2006/2007, 2007/2008, 2008/2009 e 2009/2010. Os ensaios foram instalados na época das águas, com semeadura entre outubro e novembro, nas localidades de Mococa $\left(21^{\circ} 28^{\prime}\right.$ Latitude Sul; $47^{\circ} 01^{\prime}$ Longitude Oeste, a $665 \mathrm{~m}$ de altitude) e de Capão Bonito (2350' Latitude Sul; 48³6' Longitude Oeste, a 702 m de altitude), com irrigação suplementar por aspersão.

Foi utilizado o delineamento experimental em blocos casualizados com quatro repetições. A parcela experimental, comum a todos os ensaios, foi constituída de cinco linhas de 5 metros de comprimento, espaçadas em 0,40 metros entre si. A área útil avaliada correspondeu às três linhas centrais de cada unidade experimental, que foram colhidas totalmente, perfazendo uma área de $6,0 \mathrm{~m}^{2}$.

Por se tratar de um conjunto balanceado de dados, foram conduzidas análises de variâncias (ANAVAs) individualizadas para se testar a homogeneidade dos quadrados médios residuais, conforme descrito por Pimentel-Gomes (1987). A ANAVA conjunta, no esquema fatorial triplo, considerando os efeitos de 
genótipos $(\mathrm{G})$, anos (A) e locais (L) como fixos foi conduzida para se testar o efeito da interação genótipo $\mathrm{x}$ ambiente (IGA). Diante da presença dessas interações foram obtidas estimativas de produtividade, estabilidade e adaptabilidade pelas metodologias propostas por Eberhart e Russel (1966) e Lin e Binns (1988) além da metodologia de modelos mistos proposta por Resende (2004).

Recomendada para análise de série de ensaios com dados desbalanceados, a análise de deviance (ANADEV), proposta por Resende (2007b), utilizou o método REML (Restricted Maximum Likelihood), e foi conduzida para obtenção de estimativas de componentes de variância e a significância dos efeitos do modelo foi obtida por meio do teste da razão da verossimilhança (Likelihood Ratio Test, ou LRT), estimados com o modelo saturado (completo), em relação às derivadas do modelo sem o efeito o qual se deseja testar.

Em seguida, a metodologia dos modelos mistos (REML/BLUP) foi utilizada na estimativa de parâmetros de produtividade e estabilidade: média harmônica dos valores genéticos (MHVG); produtividade e adaptabilidade: performance relativa dos valores genéticos (PRVG); produtividade, estabilidade e adaptabilidade: média harmônica da performance relativa dos valores genéticos (MHPRVG), através dos valores genotípicos estimados (VG), conforme descrito por Resende (2004).

Nas análises realizadas utilizaram-se os programas Genes (CRUZ, 2006a, 2006b) e Selegen-REML/BLUP (RESENDE, 2002).

\section{RESULTADOS E DISCUSSÃO}

Os quadrados médios da ANAVA conjunta dos oito ensaios realizados revelaram efeitos altamente significativos para todas as fontes de variação (Tabela 1), indicando diferenças significativas de comportamento tanto referentes a ano quanto aos locais avaliados.

Pelo fato de ter-se conduzido ensaios em anos e locais diferentes, supunha-se que as interações iriam ser significativas. Esse fato, por si só, não permitiria uma correta escolha dos materiais para o estado de São Paulo, o que evidenciou a necessidade do aprofundamento do estudo de adaptabilidade e da estabilidade de cada um dos genótipos. Significância para efeitos de cultivares, ambientes e interações foram relatados para a cultura do feijão (CARBONELL et al., 2004) e em linhagens diaplóides de trigo (BIUDES et al., 2009). Em arroz irrigado e em feijão, Morais et al. (2008) e Backes et al. (2005), respectivamente, apresentaram resultados altamente significativos para genótipos, ambientes e sua interação, mostrando que os genótipos sofreram influências diferenciadas dos ambientes, dificultando uma recomendação única de cultivares para toda a região em estudo. Em função desses resultados e do coeficiente de determinação $\left(\mathrm{R}^{2}\right)$ verificou-se que os efeitos de locais e suas interações (GxA, LxA e GxLxA) foram as causas predominantes da variação da produtividade das linhagens de arroz com coeficientes de determinação da ordem de 0,$19 ; 0,11$ e 0,14 , respectivamente, enquanto que o erro experimental apresentou coeficiente de 0,09, indicando boa precisão experimental, juntamente com coeficiente de variação ambiental de $18,7 \%$ no conjunto dos 8 ensaios.

Tabela 1 - Quadro da análise da variância conjunta para produção de grãos (kg ha $\left.{ }^{-1}\right)$ de 16 genótipos de arroz de terras altas de ensaios em Mococa-SP e Capão Bonito-SP nas safras de 2006/2007, 2007/2008, 2008/2009 e 2009/2010

\begin{tabular}{lccc}
\hline \multicolumn{1}{c}{ FV } & GL & QM $\left(.10^{-3}\right)$ & F \\
\hline Genótipos (G) & 15 & 4,99 & $8,97^{* *}$ \\
Locais (L) & 1 & 30,48 & $10,50^{* *}$ \\
Anos (A) & 3 & 54,55 & $18,79^{* *}$ \\
G x L & 15 & 2,75 & $4,93^{* *}$ \\
G x A & 45 & 2,07 & $3,72^{* *}$ \\
L x A & 3 & 42,35 & $14,59^{* *}$ \\
G x L x A & 45 & 1,86 & $3,35^{* *}$ \\
\hline Resíduo & 360 & 556,67 & - \\
Média & 3992 & - & - \\
CV (\%) & $18,7 \%$ & - & - \\
Maior/Menor QMR & 3,2 & - & - \\
\hline
\end{tabular}

** = significativo a $1 \%$ 
Com o uso da metodologia, baseada na regressão linear, de Eberhart e Russell (1966) no qual cada cultivar foi caracterizada pelo coeficiente de regressão linear $\left(\beta_{1 \mathrm{i}}\right)$, que representa a resposta dos tratamentos à variação do ambiente, e pela variância dos desvios da regressão obtida a partir dos quadrados médios dos desvios da regressão, foram estimados os parâmetros do modelo e apresentados na Tabela 2.

Como ocorre comumente na metodologia de Eberhart e Russell (1966) a não significância dos coeficientes $\beta_{1 \mathrm{i}}$ (VENCOVSKY; BARRIGA, 1992), foi observada em 12 genótipos, e nessas condições aceitamos a hipótese dos parâmetros da regressão serem iguais a 1, indicando a adaptação geral desses materiais. Dos 4 genótipos restantes com $\beta_{1 \mathrm{i}}$ significativos a 1 e $5 \%$, foram observados $\beta_{1 \mathrm{i}}>1$ para IAC 2010 e IAC 2011 e $\beta_{1 \mathrm{i}}<1$ nos outros dois, sendo eles BRS Curinga e IAC 2012, indicando a adaptação a ambientes favoráveis nos dois primeiros e adaptação a ambientes desfavoráveis nos dois últimos.

$\mathrm{Na}$ análise das estimativas das médias $\left(\beta_{0 \mathrm{i}}\right)$ e das variâncias dos desvios da regressão $\left(\sigma^{2} \mathrm{~d}_{\mathrm{i}}\right)$ (Tabela 2$)$ foram observados os maiores rendimentos em produtividade de grãos nos genótipos IAC 2009, IAC 1829 e IAC 2005, que tiveram produções superiores à melhor testemunha (IAC 202) em 570, 489 e $261 \mathrm{~kg} \mathrm{ha}^{-1}$, respectivamente. Tais cultivares também apresentaram valores de $\beta_{1 \mathrm{i}}$ muito próximos de 1,0 e não significativos, indicando a ampla adaptabilidade dessas linhagens. Para os três materiais em questão, estimaram-se variâncias dos desvios da regressão $\left(\sigma^{2} d_{i}\right)$, que para as linhagens IAC 1829 e IAC 2005 foram positivas e significativas, indicando uma menor estabilidade dos materiais em comparação ao genótipo IAC 2009, que obteve $\sigma^{2} \mathrm{~d}_{\mathrm{i}}$ negativo e não significativa, indicativo de maior estabilidade deste material frente àqueles com elevado desempenho nos ensaios. Utilizandose os mesmos critérios, foi possível selecionar genótipos de alfafa, submetidos a diferentes cortes, com adaptabilidade geral e alta estabilidade na produção de matéria seca, em condições com IGA altamente significativa pelo teste F. (FERREIRA et al., 2004). Borges et al. (2010) utilizaram o método de Eberhart e Russel (1966) em genótipos de arroz e destacaram a importância e a confiabilidade desse método, ressaltando sua aplicação em análises de ensaios em número pequeno de ambientes, enquanto

Tabela 2 - Estimativas de parâmetros de adaptabilidade e estabilidade para produção de grãos $\left(\mathrm{kg} \mathrm{ha}^{-1}\right)$ de 16 linhagens e variedades de arroz de terras altas no estado de São Paulo obtidas pelos métodos de Eberhart e Russell e Lin e Binns

\begin{tabular}{|c|c|c|c|c|}
\hline \multirow{2}{*}{ Cultivares/Linhagens } & \multicolumn{2}{|c|}{ Eberhart e Russell } & \multirow{2}{*}{ Médias $\left(\beta_{0 \mathrm{i}}\right) \mathrm{kg} \mathrm{ha}^{-1}$} & \multirow{2}{*}{$\frac{\text { Lin e Binns }}{\mathrm{P}_{\mathrm{i}}}$} \\
\hline & $\beta_{1 \mathrm{i}}$ & $\sigma_{\mathrm{di}}^{2}$ & & \\
\hline IAC 201 & $0,729^{\mathrm{ns}}$ & $-41614,6^{\text {ns }}$ & 3636,13 & 1328244 \\
\hline IAC 202 & $0,881^{\mathrm{ns}}$ & $460510,8 * *$ & 4119,25 & 1170505 \\
\hline BRS Curinga & $0,877^{\text {ns }}$ & $139247,5^{\mathrm{ns}}$ & 4049,75 & 1051931 \\
\hline IAC 1824 & 1,193 ns & $407775,3 * *$ & 3905,50 & 930803 \\
\hline IAC 1829 & $1,045^{\mathrm{ns}}$ & $739266,4 * *$ & 4608,75 & 367727 \\
\hline IAC 1945 & $1,318^{\mathrm{ns}}$ & $-45542,3^{\mathrm{ns}}$ & 3693,50 & 1260027 \\
\hline IAC 2004 & $0,948^{\mathrm{ns}}$ & $321439,1 * *$ & 3693,25 & 1565798 \\
\hline IAC 2005 & $1,169^{\mathrm{ns}}$ & $521529,4 * *$ & 4380,63 & 402653 \\
\hline IAC 2006 & $1,099^{\mathrm{ns}}$ & $59200,6^{\mathrm{ns}}$ & 4118,88 & 674699 \\
\hline IAC 2007 & $0,710^{\mathrm{ns}}$ & $203726,5 *$ & 3826,25 & 1053285 \\
\hline IAC 2008 & $0,960^{\mathrm{ns}}$ & $212711,9 *$ & 4237,25 & 895287 \\
\hline IAC 2009 & $0,939^{\mathrm{ns}}$ & $-60859,7^{\mathrm{ns}}$ & 4689,38 & 234242 \\
\hline IAC 2010 & $1,337 *$ & $746837,8 * *$ & 4024,13 & 1119326 \\
\hline IAC 2011 & $1,562 * *$ & $980302,9 * *$ & 3162,75 & 2770648 \\
\hline IAC 2012 & $0,620 *$ & $185912,0 *$ & 4176,00 & 796768 \\
\hline IAC 2013 & $0,614 *$ & $1300037,2 * *$ & 3471,88 & 2343019 \\
\hline Média & 1,000 & & 3987,08 & \\
\hline
\end{tabular}


que Barros et al. (2010), comparando vários métodos de análise, utilizaram, com sucesso, essa metodologia para seleção de genótipos de soja.

Visando selecionar os genótipos que aliem alta produtividade, estabilidade e adaptabilidade, aplicouse a metodologia de Lin e Binns (1988) (Tabela 2), que se baseia na comparação da produtividade observada do genótipo com a maior média em cada ambiente.

Para o conjunto de dados, foi identificado que os genótipos IAC 2009, IAC 1829, IAC 2005 apresentaram os menores valores do parâmetro $\mathrm{P}_{\mathrm{i}}$, indicando que foram os que mais se aproximaram da máxima produtividade. Os genótipos evidenciados por essa metodologia foram coincidentes àqueles evidenciados pela metodologia de Eberhart e Russell (1966). A metodologia não paramétrica proposta por Lin e Binns (1988) utiliza-se de médias fenotípicas estimadas através de procedimento convencional de ANAVA, e tem mostrado aplicação em programas de melhoramento de arroz, como em Soares et al. (2007) selecionando linhagens de arroz de terras altas em ensaios de VCU (valor de cultivo e uso). Em outras espécies, a metodologia também foi utilizada, como por Biudes et al. (2009) na seleção de linhagens diaplóides de trigo e por Ferreira et al. (2004) na seleção de cultivares de alfafa para produção de matéria seca em diferentes cortes. Os referidos trabalhos também evidenciaram a grande concordância na seleção dos genótipos com alta estabilidade e adaptabilidade que ocorreu com o uso do método da regressão linear de Eberhart e Russel (1966) e pela estimativa do parâmetro $\mathrm{P} i$, da metodologia de Lin e Binns (1988). Resultados similares foram apresentados por Ribeiro et al. (2009) e Barros et al. (2010) que utilizaram essas duas metodologias, entre outras, na identificação de cultivares de feijão e soja, nessa ordem, estáveis para produtividade de grãos com ampla adaptação a ambientes favoráveis. Já Silva e Duarte (2006) testaram 28 genótipos de soja e sugeriram que o uso desses dois métodos em combinação pode agregar informações à análise de estabilidade, em razão de suas correlações significativas e uma associação relativamente fraca entre eles, que faz com que eles atuem de forma complementar.

O resultado da análise de deviance (ANADEV), avaliada pelo teste de qui-quadrado, aplicado sobre a razão entre as verossimilhanças (LRT) do modelo completo ou saturado em relação ao modelo sem o efeito que se deseja testar (RESENDE, 2007a, 2007b), apresentado na Tabela 3, mostrou que os efeitos de genótipos $(\mathrm{G})$, e suas interações com anos (GxA) e com locais $(\mathrm{GxL})$ não foram significativos para explicar a variação total dos dados nos ensaios, enquanto que a interação tripla GxLxA apresentou-se altamente significativa $(\mathrm{p} \leq 0,01)$.

A estimativa do efeito da contribuição de cada fonte de variação através do componente de variância e seu coeficiente de determinação confirmou a grande participaçãodainteraçãotripla(33\%) sobrea diversidade total dos dados (Tabela 3). Embora não significativo, o efeito de genótipos foi o que apresentou a segunda maior contribuição relativa $(7 \%)$ para a variação observada na produtividade dos materiais avaliados. A significativa participação da IGA na amplitude de variação dos fenótipos tem sido demonstrada por diversos autores utilizando a metodologia de modelos mistos. Zeni-Neto et al. (2008) reportaram contribuição de $67 \%$ atribuída às interações para o caráter toneladas de brix por hectare de 193 clones de cana de açúcar, obtidas de três ambientes. Com resultados distintos, Borges et al. (2010) apresentaram resultados de 11 anos de experimentação em arroz de terras altas, mostrando maior contribuição das interações duplas,

Tabela 3 - Estimativas de deviance, componentes de variância e coeficientes de determinação na análise conjunta para produção de grãos de ensaios em Mococa-SP e Capão Bonito-SP nas safras de 2006/2007, 2007/2008, 2008/2009 e 2009/2010 envolvendo 13 linhagens e três cultivares de arroz de terras altas, pela metodologia de modelos mistos

\begin{tabular}{lcccc}
\hline \multicolumn{1}{c}{ Efeito } & Deviance & LRT $\left(\chi^{2}\right)$ & $\begin{array}{c}\text { Componente de Variância } \\
\left(.10^{3}\right)\end{array}$ & Coeficiente de Determinação \\
\hline Genótipos & $7081,93^{+}$ & $1,26^{\mathrm{ns}}$ & $\mathrm{Vg}=72,67$ & $\mathrm{~h}{ }^{2} \mathrm{~g}=0,07$ \\
Genótipos x locais & $7081,46^{+}$ & $0,79^{\mathrm{ns}}$ & $\mathrm{Vgl}=53,56$ & $\mathrm{c}^{2} \mathrm{gl}=0,05$ \\
Genótipos x anos & $7080,73^{+}$ & $0,06^{\mathrm{ns}}$ & $\mathrm{Vga}=19,57$ & $\mathrm{c}^{2} \mathrm{ga}=0,02$ \\
Genótipos x locais x anos & $7123,79^{+}$ & $43,12^{* *}$ & $\mathrm{Vgla}=346,78$ & $\mathrm{c}^{2} \mathrm{gla}=0,33$ \\
Resíduo & - & - & $\mathrm{Ve}=559,84$ & $\mathrm{c}^{2} \mathrm{res}=0,53$ \\
Modelo Completo & 7080,67 & - & $\mathrm{Vf}=1052,41$ & $\mathrm{c}^{2}$ total $=1,00$ \\
\hline
\end{tabular}

${ }^{+}$: Deviance estimada com o modelo sem o efeito correspondente; ${ }^{\text {ns: }}$ não significativo; ${ }^{*} \mathrm{e}^{* *}=$ significativo pelo teste de qui-quadrado a $5 \%(3,84)$ e $1 \%(6,63)$, respectivamente 
de $5,1 \%$ e $4,7 \%$ para GxL e GxA, respectivamente, que da interação tripla GxLxA, de 1,9\%, para a variação fenotípica. Verardi et al. (2009) apresentaram análise de dados de três localidades para produção de borracha obtidos de 22 progênies de seringueira no qual a contribuição de todos os efeitos das interações foi da ordem de $0,8 \%$.

Os valores genotípicos referentes à produtividade média e os desvios em relação à média geral são apresentados na Tabela 4 para cada um dos locais (Capão Bonito e Mococa), bem como a análise conjunta dos oito ensaios, de forma ordenada a partir dos maiores valores genotípicos. Na comparação entre os locais pode ser observado que os cinco genótipos com maiores valores genotípicos na análise conjunta (IAC 2009, IAC 1829, IAC 2005, IAC 2008 e IAC 2012), foram semelhantes aos dados observados em Capão Bonito, porém, não na mesma ordem. Já em Mococa, houve pequena variação, ficando na seguinte ordem decrescente: IAC 2009, IAC 1829, IAC 2010, IAC 2008 e IAC 2005.
No presente conjunto de dados o resultado da estabilidade (MHVG), da adaptabilidade (PRVG), bem como os de estabilidade e adaptabilidade dos valores genotípicos (MHPRVG) para a produtividade de grãos, são apresentados na Tabela 5.

A MHVG, que é a média harmônica dos valores genotípicos, refere-se à estabilidade e à produtividade de grãos, simultaneamente. Assim, a seleção baseada na MHVG contempla esses dois atributos conjuntamente. Como a MHVG penaliza a instabilidade, quando genótipos são avaliados em diversos locais, o resultado é que a nova média obtida é ajustada por essa penalização. Já a adaptabilidade pode ser entendida como a capacidade das linhagens responderem de forma positiva à melhoria do ambiente e por essa razão, representa uma característica de grande interesse para melhoristas de plantas no desenvolvimento de novas cultivares. $O$ procedimento da performance relativa dos valores genotípicos (PRVG), que capitaliza a capacidade de resposta de cada linhagem à melhoria do ambiente tem se mostrado um método apropriado para identificar a adaptabilidade.

Tabela 4 - Valores genotípicos de linhagens e variedades de arroz de terras altas, valores positivos estimados de desvios para produção de grãos $\left(\mathrm{kg} \mathrm{ha}^{-1}\right)$ em dois locais (Mococa, SP e Capão Bonito, SP) e na análise conjunta dos 4 anos de ensaios estimados pela metodologia dos modelos mistos

\begin{tabular}{lcccccc}
\hline \multirow{2}{*}{$\begin{array}{c}\text { Linhagens/ } \\
\text { Cultivares }\end{array}$} & \multicolumn{3}{c}{ Mococa } & \multicolumn{2}{c}{ Capão Bonito } & \multicolumn{2}{c}{ Análise Conjunta } \\
\cline { 2 - 7 } & Valores genotípicos $^{1}$ & Desvio $^{2}$ & Valores genotípicos & Desvio & Valores genotípicos & Desvio \\
\hline IAC 2009 & 4643,33 & 9,74 & 4174,22 & 11,68 & 4408,77 & 10,65 \\
IAC 1829 & 4469,07 & 5,63 & 4251,40 & 13,74 & 4360,23 & 9,43 \\
IAC 2005 & 4403,37 & 4,07 & 4042,22 & 8,15 & 4222,79 & 5,98 \\
IAC 2008 & 4446,18 & 5,08 & 3826,85 & 2,39 & 4136,51 & 3,82 \\
IAC 2012 & 4370,18 & 3,29 & 3829,21 & 2,45 & 4099,69 & 2,89 \\
IAC 202 & 4371,99 & 3,33 & 3758,99 & 0,57 & 4065,49 & 2,04 \\
IAC 2006 & 4335,10 & 2,46 & 3795,58 & 1,55 & 4065,34 & 2,03 \\
BRS Curinga & 4324,50 & 2,21 & 3722,83 & $-0,40$ & 4023,67 & 0,99 \\
IAC 2010 & 4451,03 & 5,20 & 3565,67 & $-4,60$ & 4008,35 & 0,60 \\
IAC 1824 & 4168,95 & $-1,47$ & 3704,65 & $-0,88$ & 3936,80 & $-1,19$ \\
IAC 2007 & 4006,02 & $-5,32$ & 3772,08 & 0,92 & 3889,05 & $-2,39$ \\
IAC 1945 & 4093,42 & $-3,25$ & 3524,95 & $-5,69$ & 3809,19 & $-4,40$ \\
IAC 2004 & 4137,33 & $-2,21$ & 3480,62 & $-6,88$ & 3808,98 & $-4,40$ \\
IAC 201 & 3917,83 & $-7,40$ & 3580,44 & $-4,21$ & 3749,14 & $-5,90$ \\
IAC 2013 & 3791,84 & $-10,38$ & 3559,85 & $-4,76$ & 3675,86 & $-7,74$ \\
IAC 2011 & 3766,36 & $-10,98$ & 3213,04 & $-14,04$ & 3489,71 & $-12,41$ \\
\hline Média Geral & 4231,03 & & 3737,66 & & 3984,35 & \\
\hline
\end{tabular}

${ }^{1}$ : Valores genotípicos $=\left(\mu_{\mathrm{j}}+\mathrm{g}+\mathrm{gem}\right)$ :média geral mais o efeito do genótipo e a interação média em kg ha ${ }^{-1} ;{ }^{2}:$ Desvio em função da média geral, em porcentagem 
Tabela 5 - Estabilidade de valores genotípicos (MHVG), adaptabilidade de valores genotípicos (PRVG), estabilidade e adaptabilidade de valores genotípicos (MHPRVG) para produção de grãos ( $\left.\mathrm{kg} \mathrm{ha}^{-1}\right)$ de linhagens e variedades de arroz para terras altas estimados pela metodologia dos modelos mistos

\begin{tabular}{|c|c|c|c|c|c|}
\hline Linhagens/Cultivares & MHVG & PRVG & $\mathrm{PRVG}^{*} \mathrm{MG}^{1}$ & MHPRVG & MHPRVG*MG \\
\hline IAC 2009 & 4396,30 & 1,11 & 4411,16 & 1,11 & 4410,83 \\
\hline IAC 1829 & 4357,52 & 1,10 & 4370,25 & 1,10 & 4364,26 \\
\hline IAC 2005 & 4215,08 & 1,06 & 4227,82 & 1,06 & 4226,26 \\
\hline IAC 2008 & 4113,33 & 1,04 & 4133,19 & 1,04 & 4132,00 \\
\hline IAC 2012 & 4081,85 & 1,03 & 4098,66 & 1,03 & 4098,00 \\
\hline IAC 2006 & 4047,44 & 1,02 & 4064,22 & 1,02 & 4064,14 \\
\hline IAC 202 & 4042,38 & 1,02 & 4062,09 & 1,02 & 4061,30 \\
\hline BRS Curinga & 4001,17 & 1,01 & 4020,45 & 1,01 & 4019,78 \\
\hline IAC 2010 & 3959,46 & 1,00 & 3996,26 & 1,00 & 3986,72 \\
\hline IAC 1824 & 3923,11 & 0,99 & 3937,52 & 0,99 & 3937,49 \\
\hline IAC 2007 & 3885,53 & 0,98 & 3896,75 & 0,98 & 3892,78 \\
\hline IAC 1945 & 3787,98 & 0,96 & 3806,18 & 0,96 & 3805,56 \\
\hline IAC 2004 & 3780,67 & 0,95 & 3803,23 & 0,95 & 3800,96 \\
\hline IAC 201 & 3741,54 & 0,94 & 3753,07 & 0,94 & 3751,99 \\
\hline IAC 2013 & 3672,19 & 0,92 & 3682,78 & 0,92 & 3679,38 \\
\hline IAC 2011 & 3467,77 & 0,87 & 3485,93 & 0,87 & 3484,87 \\
\hline
\end{tabular}

${ }^{1}:$ Média Geral

O método da média harmônica da performance relativa dos valores genotípicos (MHPRVG), se baseia em valores genotípicos preditos, via modelos mistos, e agrupa, em uma única estatística, a estabilidade, a adaptabilidade e a produtividade, facilitando, de modo singular, a seleção de genótipos superiores. O método MHPRVG é similar ao método de Lin e Binns (1988), com a ressalva de que é realizado sobre os valores genotípicos e não fenotípicos.

Observou-se que as estimativas MHVG, PRVG e MHPRVG (Tabela 5) classificaram os genótipos de forma semelhante quando se utilizou cada um dos três parâmetros obtidos pelo procedimento de BLUP. Quando se comparou tal classificação com a obtida a partir dos valores genotípicos, derivados da análise conjunta dos oito ambientes de avaliação (Tabela 4), observou-se que estes também foram classificados de forma semelhante.

\section{CONCLUSÕES}

1.O programa de melhoramento genético de arroz de terras altas para o estado de São Paulo tem produzido linhagens com desempenho superior às cultivares utilizadas como testemunhas;
2. Dentre as linhagens avaliadas, IAC 2009, IAC 1829, IAC 2005 foram as que apresentam o melhor desempenho agronômico perante as metodologias propostas, revelando apresentar estabilidade, adaptabilidade e produtividade superiores;

3.Dentre as metodologias aplicadas, o método MHPRVG foi vantajoso por apresentar os resultados na mesma escala de medição do caráter avaliado e de forma simultânea.

\section{REFERÊNCIAS}

BACKES, R. L. et al. Adaptabilidade e estabilidade de genótipos de feijoeiro no Estado de Santa Catarina. Acta Scientiarum Agronomy, v. 27, n. 2, p. 309-314, 2005.

BARROS, H. B. et al. Análise de adaptabilidade e estabilidade em soja (Glycine $\max$ L.) em Mato Grosso. Ambiência, v. 6, n. 1, p. 75-88, 2010.

BASTOS, I. T. et al. Avaliação da interação genótipo x ambiente em cana-de-açúcar via modelos mistos. Pesquisa Agropecuária Tropical, v. 37, n. 4, p. 195-203, 2007.

BIUDES, Barnabé et al. Adaptabilidade e estabilidade de linhagens diaplóides de trigo Bragantia, v. 68, n. 1, p. 63-74, 2009. 
BORGES, V. et al. Desempenho genotípico de linhagens de arroz de terras altas utilizando metodologia de modelos mistos. Bragantia, v. 69, n. 4, p. 833-841, 2010.

BUENO FILHO, J. S. S.; VENCOVSKY, R. Alternativas de análise de ensaios em látice no melhoramento vegetal. Pesquisa Agropecuária Brasileira, v. 35, n. 2, p. 259-269, 2000.

CARBONELL, S. A. M. et al. Common bean cultivars and lines interactions with environments. Scientia Agricola, v. 61, n. 2, p. $169-177,2004$.

CARBONELL, S. A. M. et al. Estabilidade de cultivares e linhagens de feijoeiro em diferentes ambientes no estado de São Paulo. Bragantia, v. 66, n. 2, p. 193-201, 2007.

CRUZ, C. D. Programa Genes - Biometria. Viçosa, MG: Editora UFV, 2006a. 382 p. v. 1.

CRUZ, C. D. Programa Genes - Estatística Experimental e Matrizes. Viçosa: Editora UFV, 2006b.285 p. v. 1.

EBERHART, S. A.; RUSSELL, W. A. Stability parameters for comparing varieties. Crop Science, v. 6, n. 1, p. 36-40, 1966.

FERREIRA, R. P. et al. Adaptabilidade e estabilidade de cultivares de alfafa em relação a diferentes épocas de corte. Ciência Rural, v. 34, n. 1, p. 265-269, 2004.

LIN, C. S.; BINNS, M. R. A superiority measure of cultivar performance for cultivar $\mathrm{x}$ location data. Canadian Journal of Plant Science, v. 68, p. 193-198, 1988.

MORA, F.; PUPIM JUNIOR, F.; SCAPIM, C. A. Prediccion del efecto de cultivares de algodón em la presencia de interacción genotipo-ambiente. Ciencia e Investigacion Agraria, v. 34, n. 1, p. 13-21, 2007.

MORAIS, L. K. et al. Adaptabilidade e estabilidade fenotípica de genótipos de arroz irrigado para o estado de São Paulo. Revista Biociências, v. 14, n. 1, p. 9-16, 2008.

OLIVEIRA, R. A. et al. Genotypic evaluation and selection of sugarcane clones in three environments in the state of Paraná.Crop Breeding and Applied Biotechnology, v. 5, n. 4, p. 426-434, 2005.

PIEPHO, H. P.; MÖHRING, J. Best linear unbiased prediction of cultivar effects for subdivided target regions. Crop Science, v. 45, n. 3, p. 1151-1159, 2005.

PIMENTEL-GOMES, F. Curso de estatística experimental. Piracicaba: Nobel, 1987. 468 p.

PURBA, A. R. et al. Prediction of oil palm (Elaeis guineensis Jacq.) agronomic performances using the best linear unbiased predictor (BLUP). Theoretical and Applied Genetics, v. 102, n. 5, p. 787-792, 2001.

RESENDE, M. D. V. Matemática e estatística na análise de experimentos e no melhoramento genético. Colombo: Embrapa Florestas, 2007a. 561 p.

RESENDE, M. D. V. SELEGEN-REML/BLUP: sistema estatístico e seleção genética computadorizada via modelos lineares mistos. Colombo: Embrapa Florestas, 2007b. 361 p.

RESENDE, M. D. V. Métodos estatísticos ótimos na análise de experimentos de campo. Colombo: Embrapa Florestas, 2004. 65 p. (Documentos, 100)

RESENDE, M. D. V. Genética biométrica e estatística no melhoramento de plantas perenes. Brasília: Embrapa Informação Tecnológica, 2002. 975 p.

RESENDE, M. D. V. et al. Estimação de componentes de variância e predição de valores genéticos pelo método da máxima verossimilhança restrita (REML) e melhor predição linear não viciada (BLUP) em pinus. Boletim de Pesquisa Florestal, v. 32-33, p. 23-42, 1996.

RIBEIRO, N. D. et al. Estabilidade de produção de cultivares de feijão de diferentes grupos comerciais no estado do Rio Grande do Sul. Bragantia, v. 68, n. 2, p. 339-346, 2009.

SILVA, W. C. J.; DUARTE, J. B. Métodos estatísticos para estudo de adaptabilidade e estabilidade fenotípica em soja. Pesquisa Agropecuária Brasileira, v. 41, n. 1, p. 23-30, 2006.

SOARES, A. A. et al. Stability of upland rice lines in Minas Gerais, Brazil. Crop Breeding and Applied Biotechnology, v. 7, p. 394-398, 2007.

VENCOVSKY, R.; BARRIGA, P. Genética biométrica no fitomelhoramento. Ribeirão Preto: Sociedade Brasileira de Genética, 1992. 496 p.

VERARDI, C. K. et al. Adaptabilidade e estabilidade da produção de borracha e seleção em progênies de seringueira. Pesquisa Agropecuária Brasileira, v. 44, n. 10, p. 12771282, 2009.

YAN, W.; RAJCAN, I. Prediction of cultivar performance based on single versus multiple-year tests in soybean. Crop Science, v. 43, n. 2, p. 549-555, 2003.

ZENI-NETO, Hugo et al. Seleção para produtividade, estabilidade e adaptabilidade de clones de cana de açúcar em três ambientes no estado do Paraná via modelos mistos. Scientia Agraria, v. 9, n. 4, p. 425-430, 2008. 